\title{
Microbial Profile and Antibiogram Pattern of UTI in Pregnant Women at a Saudi Hospital
}

\author{
Maha A. Abo-Shadi ${ }^{*}$, Amal S. Al-Johani² \\ ${ }^{1} \mathrm{PhD}$, Microbiology and Immunology Department, Faculty of Pharmacy, Al-Azhar University, Cairo, Egypt. \\ ${ }^{2}$ MD, Biology Department, Faculty of Science, Taibah University, AlMadinah, Saudi Arabia.
}

\begin{abstract}
Introduction: Urinary tract infections (UTIs) are among the most common bacterial infections during pregnancy.

Aims: To determine the incidence, predisposing factors, microbiological and antimicrobial resistance patterns in UTI pregnant women in a Saudi hospital and comparing the antibacterial activities of these antibiotics with a probiotic.

Methodology: Urine cultures were performed to all cases $(n=1045)$ using different media. Microorganisms were identified by colony morphology, Gram stain and biochemical profiles. $\mathrm{BD}$ Phoenix ${ }^{\mathrm{TM}}$ was used in confirmation of identification of all UTI Gram-negative isolates. Antibiotic susceptibility pattern of isolates was done using disk diffusion method. Antagonistic activity of six lactobacillus plantarum isolates against different indicator bacteria was determined by agar well diffusion method.

Results: A total of 148 UTI women were detected. The most prevalent UTI isolates were E.coli $(26.1 \%)$, followed by Klebsiella spp. (20\%), Enterococcus spp. (9.5\%) CoNS $(8.8 \%)$ and Pseudomonas spp. (5.4\%). Lactobacillus plantarum showed inhibitory effect on the tested isolates.

Conclusion: Our study revealed that $14.2 \%$ of pregnant women had urinary tract infection in their pregnancy. Doing the
\end{abstract}

\section{INTRODUCTION}

Urinary tract infection (UTI) is the predominant type of bacterial infection among pregnant women ${ }^{1-2}$. As many as $90 \%$ of UTIs are caused by Escherichia coli ${ }^{3}$. Hormonal and physiological changes in the urinary tract, including ureteral dilatation and changes in bladder volume and tone, may promote infection in pregnant women. Moreover, it has been observed that pregnant women have a propensity to develop recurrent UTIs². Overall, UTI can be dangerous for both the mother and fetus. Complications that may arise include preterm delivery and increased incidence of intrauterine growth restriction. To a lesser degree, preeclampsia, caesarean delivery, anemia, sepsis, and septic shock may also be associated with UTI in these patients ${ }^{4}$.

It is worth mentioning that asymptomatic infection could be easily transfer to symptomatic infection if it is not treated probably5; and accordingly, lead to infant morbidity and mortality if poorly diagnosed $^{6}$. An accurate and prompt diagnosis of UTI is important in shortening the disease course and for preventing the ascent of the infection to the upper urinary tract and renal failure. Treatment necessary tests for pregnant women especially urine analysis and urine culture is essential to avoid UTI. The inhibitory effect of Lactobacillus plantarum on UTI pathogens appeared promising.

Keywords: Urinary Tract Infection (UTI); pregnant women; Antibiogram; Antimicrobial resistance; Lactobacilli; Saudi.

*Correspondence to:
Maha A. Abo-Shadi,
PhD, Professor,
Microbiology and Immunology Dept.,
Faculty of Pharmacy (Girls),
Al-Azhar University, Cairo, Egypt.
Article History:
\begin{tabular}{|l|c|} 
Received: 19-10-2016, Revised: 27-10-2016, Accepted: 19-11-2016 \\
\hline \multicolumn{2}{|c|}{ Access this article online } \\
\hline $\begin{array}{l}\text { Website: } \\
\text { www.ijmrp.com }\end{array}$ \\
\hline $\begin{array}{l}\text { Dol: } \\
\text { 10.21276/ijmrp.2016.2.6.014 }\end{array}$
\end{tabular}

of UTI cases is often started empirically. Therapy is based on information determined from the antimicrobial resistance pattern of the urinary pathogens. However, because of the evolving and continuing antibiotic resistance phenomenon, regular monitoring of resistance patterns is necessary to improve guidelines for empirical antibiotic therapy ${ }^{7}$. This resistance problem needs a renewed effort, to search for new antimicrobial substances from various sources like probiotics.

There has been increased focus on the use of probiotics such as Lactobacillus sp. for prophylaxis and treatment of UTI8.

In the present study, we have determined the prevalence of UTI in pregnant women admitted to a certain Saudi hospital and the maternal risk factors for causing UTIs. Providing information to health officials about the main pathogens responsible for UTI in those pregnant women and recognizing the most susceptible antibiotics against them were also determined. We have also measured the antibacterial activities of some probiotics on some isolates. 


\section{MATERIALS AND METHODS}

The present retrospective study was conducted in $\mathrm{MMCH}$, Madinah Munawarah city, located in the western part of Saudi Arabia, during one year period from 1 July 2009 to 30 June 2010. The hospital has 500 beds, and provides primary, secondary and tertiary health care. It is also the main referral hospital for Madinah region. Urine samples were collected from a total of 1045 pregnant women that were suspected of having UTIs. Urine samples were obtained by informed consent of the pregnant women included in this study. Ethical Committee of the Madinah Maternity and Children's Hospital \& the Scientific Committee of Taibah University approved the study. Clinical data collected from each woman included age, gestational age, and parity. The first midstream urine passed by the patient at the beginning of the day is the most concentrated and therefore the most suitable for culture, microscopy, and biochemical analysis ${ }^{9}$.

Isolation, Identification and Antibiotic Susceptibility Testing of Microbial Isolates from UTI Cases

After shaking each urine sample, a loopful was streaked on different plates of MacConkey agar, CLED agar, Sabaroud dextrose agar and Blood agar for microbial isolation. After incubation aerobically at $35-37 \circ \mathrm{C}$, plates with growth were selected. The colonies were isolated using an inoculating loop and subsequently, subcultured on agar slants for use in further tests ${ }^{10}$. Identification of uropathogens was done based on colony morphology, Gram staining, test results of catalase, coagulase, oxidase, urease, germ tube, optochin, bacitracin and biochemical profiles using API tests (BioMérieux, France) specific for Gramnegative organisms. BDPhoenix ${ }^{\mathrm{TM}} \mathrm{NMIC/ID}$ panels were also used to confirm the identification of all UTI Gram-negative isolates. Furthermore, antibiotic susceptibility testing was done according to National Committee for Clinical Laboratory Standards ${ }^{11}$.

In vitro effect of lactobacillus spp. on the tested isolates by agar diffusion method

The selected (indicator) bacteria were: 2 standard strains E.coli ATCC 29922, S. aureus ATCC 29923, and the 4 most resistant isolates (E.coli, S. aureus, Enterobacter spp., Klebsiella spp.)

At the same time the six lactobacillus spp. (L. plantarum),that was provided from Dr. Ola Aly Abd El-Rahman, Microbiology Department, faculty of Pharmacy, AlAzhar University. The probiotic material was inoculated into DeMan Rogosa Sharpe (MRS) broth and incubated at $37^{\circ} \mathrm{C}$ for 48 hours. After incubation loopful of culture was streaked on the surface of MRS plates and incubated for $24 \mathrm{hrs}$ at $37^{\circ} \mathrm{C}$.

Afterwards, the isolates were selected and characterized on the basis of morphological , cultural and biochemical characteristics and were identified according to Bergey's Manual of Systematic Bacteriology.

Lactobacillus isolates then were cultured on MRS broth and incubated at $37^{\circ}$ for 24 hour. After centrifugation at $10,000 \mathrm{rpm}$ for $5 \mathrm{~min}$, the supernatants of lactobacilli strains were monitored for antibacterial activity against indicator bacteria as described by Ashraf et al. (2009) ${ }^{12}$.

Table 1: Microscopic and biochemical examination of urine samples from UTI pregnant women (NO = 148)

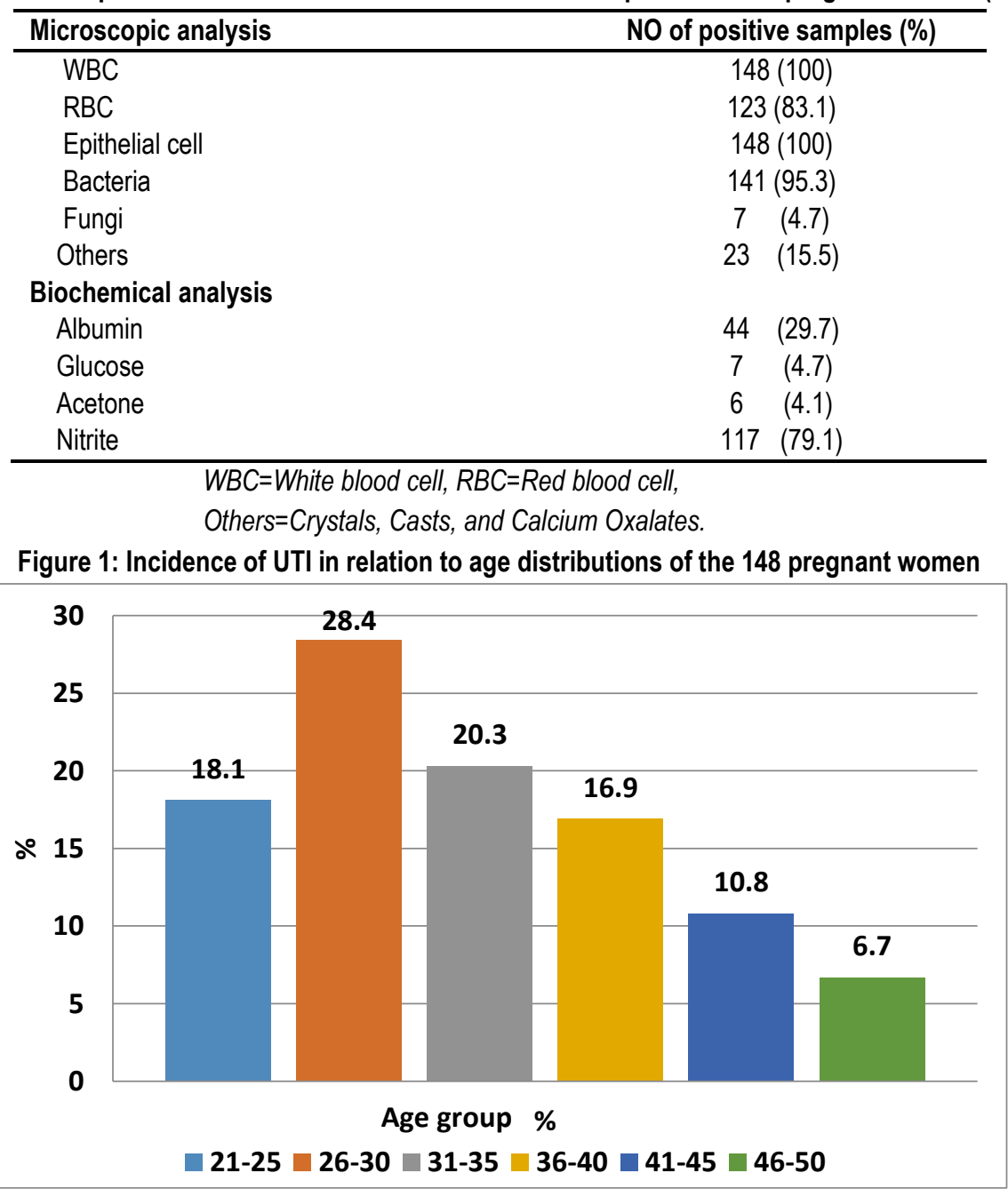


Maha A. Abo-Shadi \& Amal S. Al-Johani. Microbial Profile and Antibiogram Pattern of UTI in Pregnant Women

Table 2: Incidence of UTI by gestational age (age of pregnancy) among the 148 pregnant women

\begin{tabular}{lc}
\hline Age of pregnancy & No. of cases $\%$ \\
\hline $\mathbf{3}$ & 9.4 \\
$\mathbf{4}$ & 12.2 \\
$\mathbf{5}$ & 13.5 \\
$\mathbf{6}$ & 19.6 \\
$\mathbf{7}$ & 25.7 \\
$\mathbf{8}$ & 14.9 \\
$\mathbf{9}$ & 4.7 \\
\hline
\end{tabular}

Table 3: Incidence of UTI by parity (No. of pregnancy) among the 148 pregnant women

\begin{tabular}{lc}
\hline Parity & No of positive \\
& cases $(\%)$ \\
\hline First pregnancy & $26 \quad(17.6)$ \\
$2^{\text {nd }}$ pregnancy & $40 \quad(27)$ \\
$3^{\text {rd }}$ pregnancy and above & $82(55.4)$ \\
Total & $148 \quad(100)$ \\
\hline
\end{tabular}

\section{RESULTS}

Microscopic and biochemical data

The overall prevalence of UTI infection among the suspected cases was $14.2 \%$ (148/1045). From table 1, WBCs and epithelial cells were detected in all urine samples. Moreover, Bacteria and fungi constituted $95.3 \%$ and $4.7 \%$ of the positive samples, respectively. UTIs were most common in pregnant women with the ages between 26-30 years (Figure 1). The highest rate of UTIs in the pregnant women was during the seventh month of pregnancy (Table 2). From Table 3, the highest incidence of UTIs was in women in third pregnancy and above.

Microbiological data

During the study period (July 2009 to June 2010), 1045 suspected UTI in pregnant women were admitted to $\mathrm{MMCH}$.

A total of 148 microbial isolates were isolated from the 148 cases. $70.9 \%$ of the total cases was from in-patient department, while $29.1 \%$ was from out-patient department. The most prevalent UTI isolates were E.coli $(26.1 \%)$, followed by Klebsiella spp. (20\%), Enterococcus spp. (9.5\%) CoNS (8.8\%) and Pseudomonas spp. (5.4\%) (Table 4) Antibacterial resistance rate of UTI Gram-positive and negative isolates is shown in tables $5 \& 6$ respectively. L5 \& L6 gave the best inhibitory activity against the tested organisms as seen in Table 7.

Table 4: Different microbial isolates from the 148 UTI pregnant women

\begin{tabular}{lc}
\hline Microbial isolates & No (\%) \\
\hline Gram-positive organisms & $55(37.2)$ \\
CoNS & $13(8.8)$ \\
MRSA & $3(2 \%)$ \\
MSSA & $10(6.8 \%)$ \\
Streptococcus viridans & $4(2.7)$ \\
Streptococcus agalactiae & $6(4.1)$ \\
Streptococcus pneumoniae & $5(3.4)$ \\
Enterococcus faecalis & $9(6.1)$ \\
Enterococcus faecium & $5(3.4)$ \\
Gram-negative organisms & $86(58.1)$ \\
E.coli & $32(21.6)$ \\
Klebsiella pneumoniae & $24(16.2)$ \\
Klebsiellaoxytoca & $6(4.1)$ \\
Pseudomonas aeruginosa & $8(5.4)$ \\
Enterobacter cloacae & $10(6.8)$ \\
Enterobacter aerogenes & $3(2)$ \\
Acinetobacter spp. & $2(1.4)$ \\
Proteus mirabilis & $1(0.7)$ \\
Fungi & $7(4.7)$ \\
Candida albicans & $4(1.3)$ \\
Candida albicansspp.Non & $3(2)$ \\
Total no. of isolates & $148(100)$ \\
\hline CoNS Coagr & \\
\hline &
\end{tabular}

CoNS= Coagulase-negative staphylococci,

MRSA=methicillin resistance staphylococcus aureus,

$M S S A=$ methicillin sensitive staphylococcus aureus. 
Maha A. Abo-Shadi \& Amal S. Al-Johani. Microbial Profile and Antibiogram Pattern of UTI in Pregnant Women

Table 5: Antibacterial resistance rate of UTI Gram-positive isolates (No = 55)

\begin{tabular}{lcccc}
\hline Antibacterials & \multicolumn{4}{c}{ Antibacterial resistance rates No. (\%) } \\
\hline & CoNS & S. aureus & Streptococcus & Enterococcus \\
& No $=13$ & No $=13$ & spp. No = 15 & spp. No =14 \\
PG (10 IU) & $11(84.6)$ & $13(100)$ & $13(86.6)$ & $14(100)$ \\
E $(\mathbf{1 5} \boldsymbol{\mu g})$ & $10(76.9)$ & $1(7.7)$ & $5(33.3)$ & $14(100)$ \\
AP $(\mathbf{1 0} \boldsymbol{\mu g})$ & $12(92.3)$ & $13(100)$ & $10(66.6)$ & $14(100)$ \\
KF $(\mathbf{3 0} \boldsymbol{\mu g})$ & $7(53.8)$ & $0(0)$ & $4(26.7)$ & $14(100)$ \\
CD $(\mathbf{2} \boldsymbol{\mu g})$ & $9(69.2)$ & $1(7.7)$ & $5(33.7)$ & $13(92.9)$ \\
TS $(\mathbf{2 5} \boldsymbol{\mu g})$ & $7(53.8)$ & $1(7.7)$ & $11(73.3)$ & $10(71.4)$ \\
VA $(\mathbf{3 0} \boldsymbol{\mu g})$ & $6(46.2)$ & $2(15.4)$ & $4(26.7)$ & $0(0.00)$ \\
\hline
\end{tabular}

$P G=$ Penicillins $G, E=$ Erythromycin, $A P=$ Ampicillin, $K F=$ Cephalothin,

$C D=$ Clindamycin, $T S=$ Cotrimoxazole,$V A=$ Vancomycin

Table 6: Antibacterial resistance rate of UTI Gram-negative isolates (No = 86)

\begin{tabular}{|c|c|c|c|c|c|c|}
\hline \multirow[b]{2}{*}{ Antibacterials } & \multicolumn{6}{|c|}{ Antibacterial resistance rates No (\%) } \\
\hline & E. coli & $\begin{array}{l}\text { Klebsiella } \\
\text { spp. } \\
\text { No }=30\end{array}$ & $\begin{array}{c}\text { Enterobacter } \\
\text { spp. } \\
\text { No }=13\end{array}$ & $\begin{array}{c}P . \\
\text { aeruginosa } \\
\text { No }=8\end{array}$ & $\begin{array}{c}\text { Acinetobacter } \\
\text { spp. } \\
\text { No }=2\end{array}$ & $\begin{array}{c}\text { Proteus } \\
\text { mirabilis } \\
\text { No }=1\end{array}$ \\
\hline NA $(30 \mu g)$ & $10(31.3)$ & $8(26.7)$ & $10(76.9)$ & $7(87.5)$ & $2(100)$ & $0(0)$ \\
\hline NI $(300 \mu g)$ & $6(18.8)$ & $9(30.0)$ & $4(30.8)$ & $4(50.0)$ & $2(100)$ & $0(0)$ \\
\hline KF $\quad(30 \mu g)$ & $31(96.9)$ & $30(100)$ & $11(84.6)$ & $8(100)$ & $2(100)$ & $0(0)$ \\
\hline AP $\quad(25 \mu \mathrm{g})$ & $27(84.4)$ & $29(96.7)$ & $13(100)$ & $8(100)$ & $2(100)$ & $1(100)$ \\
\hline TS $\quad(25 \mu \mathrm{g})$ & $24(75.0)$ & $22(73.3)$ & $1(7.7)$ & $8(100)$ & $2(100)$ & $1(100)$ \\
\hline NOR $(10 \mu \mathrm{g})$ & $5(15.6)$ & $8(26.7)$ & $4(30.8)$ & $5(62.5)$ & $1(50.0)$ & $0(0)$ \\
\hline AK $\quad(30 \mu g)$ & $0(0)$ & $1(3.3)$ & $0(0)$ & $0(0)$ & $1(50.0)$ & $0(0)$ \\
\hline CAZ $(30 \mu g)$ & $6(18.8)$ & $11(36.7)$ & $0(0)$ & $2(25.0)$ & $1(50.0)$ & $0(0)$ \\
\hline ATM $(30 \mu \mathrm{g})$ & $6(18.8)$ & $11(36.7)$ & $0(0)$ & $2(25.0)$ & $2(50.0)$ & $0(0)$ \\
\hline IMI $(10 \mu \mathrm{g})$ & $0(0)$ & $0(0)$ & $0(0)$ & $0(0)$ & $0(0)$ & $0(0)$ \\
\hline CIP $(5 \mu g)$ & $3(9.4)$ & $2(6.7)$ & $0(0)$ & $0(0)$ & $1(50.0)$ & $0(0)$ \\
\hline AUG $(30 \mu \mathrm{g})$ & $9(28.1)$ & $17(56.7)$ & $11(84.6)$ & $8(100)$ & $1(50.0)$ & $1(100)$ \\
\hline 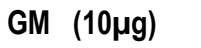 & $4(12.5)$ & $8(26.7)$ & $0(0)$ & $0(0)$ & $1(50.0)$ & $0(0)$ \\
\hline FOX $(30 \mu \mathrm{g})$ & $0(0)$ & 7 (23.3) & $12(92.3)$ & $8(100)$ & $1(50.0)$ & $1(100)$ \\
\hline
\end{tabular}

$N A=$ Nalidixic acid, $N I=$ Nitrofurantoin, $C A Z=$ Ceftazidime,,$K F=$ Cephalothin, $F O X=$ Cefoxitin,

$A P=$ Ampicillin, $A T M=$ Aztreonam, $I M I=I m i p e n e m, A U G=$ Augmentin, $G M=$ Gentamicin,

Ak= Amikacin, $C I P=$ Ciprofloxacin, $T S=$ cotrimoxazole, NOR=Norfloxacin.

Table 7: Effect of the different Lactobacillus plantarum on the tested microorganisms

\begin{tabular}{|c|c|c|c|c|c|c|}
\hline \multirow[b]{2}{*}{$\begin{array}{l}\text { Lactobacillus } \\
\text { plantarum (LP) }\end{array}$} & \multicolumn{6}{|c|}{ Diameter of inhibition zone (mm) } \\
\hline & $\begin{array}{c}\text { E.coli ATCC } \\
25922\end{array}$ & $\begin{array}{c}\text { S. aureus ATCC } \\
25923\end{array}$ & E.coli & S. aureus & $\begin{array}{c}\text { Enterobacter } \\
\text { spp. }\end{array}$ & $\begin{array}{c}\text { Klebsiella } \\
\text { spp. }\end{array}$ \\
\hline LP1 & 16 & 12 & 10 & $\mathrm{R}$ & 12 & 18 \\
\hline LP2 & 17 & 7 & 15 & 1 & 7 & 17 \\
\hline LP3 & 10 & 15 & 10 & 1 & 15 & 15 \\
\hline LP4 & 16 & $\mathrm{R}$ & $\mathrm{R}$ & $\mathrm{R}$ & $\mathrm{R}$ & 12 \\
\hline LP5 & 17 & 17 & 15 & 14 & 17 & 18 \\
\hline LP6 & 12 & 19 & 20 & 2 & 19 & 20 \\
\hline
\end{tabular}

\section{DISCUSSION}

Screening for and treatment of asymptomatic bacteriuria in pregnancy has become a standard of obstetric care and most antenatal guidelines include routine screening for $\mathrm{it}^{13}$.
The overall prevalence of UTI infection among the suspected cases was $14.2 \%$ which coincides with a study from Saudi Arabia $(14.2 \%)^{14}$. Moreover, lower rates $(4.8 \%$ and $6.1 \%)$ were recorded in neighbor countries as $\mathrm{UAE}^{15}$ and $\operatorname{Iran}^{16}$. Other researchers 
reported a higher prevalence rate in pregnant women as $(50 \%)^{13}$, $(47.5 \%)^{10},(43.1 \%)^{17}$. Such a difference could be due to geographic location and difference in environmental conditions ${ }^{18}$, and also due to improved health care.

In the current study, the urine samples were microscopically analyzed. All samples contained pus cells and epithelial cells while RBCs were found in $83.1 \%$ of total cases. Bacteria also were present in $95.3 \%$ and fungi in $4.7 \%$ of all our samples. Pus cells $(62.5 \%)$ and the yeast cells $(16.7 \%)$ in UTI pregnant women have been detected ${ }^{10}$

Pus cells in $26.0 \%, \mathrm{RBC}$ in $9.7 \%$, yeast cells in $1.6 \%$ and Trichomonas vaginalis in $0.8 \%$ of the positive 53 pregnant women have been revealed ${ }^{17}$.

The highest incidence of UTIs among pregnant women within the age group of 26-35 years (48.7\%). This may be explained by the fact that women in this age group are more sexually active. The anatomical relationship of the female urethra to the vagina makes it liable to trauma during sexual intercourse which could result in increased tendency of bacteria being massaged up the urethra into the bladder ${ }^{19}$. Similarly, the highest incidence of UTI belonged to age group 26-35 years (47\%) was found ${ }^{13}$. On the other hand, age groups 38-42 showed the highest incident rate of UTI $(66.7 \%)^{17}$.

In our study, there was a high incidence of UTIs among pregnant women within the seventh $(25.7 \%)$ and sixth (19.6\%) pregnancy month. Similar finding was reported who reported that women in the 6 and 7 months of their pregnancy had the highest prevalence of UTIs (50.0 and $71.4 \%$, respectively) ${ }^{10}$.

The incidence of UTIs by parity was found to be the highest during the third pregnancy and above (55\%). So, parity may be possible factor affecting the incidence and prevalence rate of UTIs among women. $58.3 \%$ of the women who had UTIs were in their $3^{\text {rd }}$ pregnancy and above; $43.7 \%$ were in their $2^{\text {nd }}$ pregnancy and $42.5 \%$ were in their 1 st pregnancy ${ }^{10}$.

The predominant organisms associated with UTI in Saudi Arabia are Gram negative bacteria which are highly resistant to commonly used oral agents ${ }^{20}$. In our study, Gram-positive, Gramnegative and yeast accounted for $37.2 \%, 58.1 \%$ and $7.4 \%$ of the total isolates, while they were $78.2 \%, 20.8 \%$ and $1 \%$, respectively ${ }^{21}$. Detection of Gram-negative bacteria isolates were more prevalent $(78 \%)$ than gram-positive bacteria isolates $(20 \%)$ and yeast cell like candida $(2 \%)^{13}$.

Our finding is similar to other reports which suggested that Gramnegative bacteria, particularly $E$. coli is the most common pathogen isolated in patients with UTI 22-23-5. The top five isolates in this investigation were E. coli (21.6\%), Klebsiella spp. (20.3\%), Enterococcus (9.5\%), CoNS (8.8\%) and Pseudomonas spp. (5.4\%). Similarly, the commonest causes of UTI were E. coli (48.7 $\%)$, K. pneumonia (23.9\%), S. aureus (19\%) and Pseudomonas spp. (2\%) were reported ${ }^{24}$. Furthermore, Escherichia coli (43.2\%), Klebsiella species $(20.8 \%)$, Enterobacter species $(20.8 \%)$ and Pseudomonas species (8.9\%) as the most prevalent isolates ${ }^{7}$. E.coli in 56\%, 15\% Staphylococcus aureus, 11\% Enterococci, $8 \%$ Klebsiella, 5\% Staph. saprophyticus, 2\% Proteus mirabilis, 2\% were belonged to Candida albicans and single one case was due to Citrobacter ${ }^{13}$.

In another study, Escherichia coli (35.8\%) was the most predominant organism followed by Staphylococcus aureus (20.8\%), Coliforms (17.0\%), Klebsiella pneumoniae (13.2\%),
Pseudomonas aeruginosa (1.9\%), Streptococcus faecalis (1.9\%), Proteus mirablis $(1.9 \%)$ and mixed culture of Staphylococcus epidermis and Candida albicans $(7.5 \%)^{17}$.

Empirical antibiotic selection should be based on the knowledge of local prevalence of bacterial organism and sensitivities rather than on universal guidelines ${ }^{25}$. Many, if not most, of the Gulf Corporation Council (GCC) countries do not have well-defined guidelines for antimicrobial use and lack policies for restricting and auditing antimicrobial prescriptions. There are no guidelines for the use of antimicrobials in the animal industries either. Thus, it is not surprising that antimicrobial resistance has emerged in these countries ${ }^{26}$.

Gram-negative isolates in our investigation showed a very low level of resistance to amikacin $(1.4 \%)$, imipenem $(2 \%)$, ciprofloxacin (3.4\%) and gentamicin (8.8\%). Our results agree with a study who found that the most effective antibiotics against Gram-negative isolates were imipenem and amikacin ${ }^{27}$. The most effective antibiotics against Gram-negative bacteria were imipenem and meropenem were reported 28 .

Similarly, low level of resistance to amikacin (5.5\%) and gentamicin (15.2\%) was detected ${ }^{24}$. In another study, the overall imipenem resistance was $8 \%$ for Klebsiella pneumoniae, whereas, other isolates of uropathogens were found to be $100 \%$ sensitive to imipenem? .

In our study, E.coli showed high resistance to cephalothin $(96.9 \%)$, and to ampicillin (84.4\%), but susceptible to imipenem, amikacin and cefoxitin, while Klebsiella spp. were most resistant to cephalothin \& ampicillin. A study detected that the most common causative pathogen E.coli was $100 \%$ sensitive to Linezolid and Imipenem; and Klebsiella was $87.5 \%$ sensitive to linezolid, ofloxacin and imipenem ${ }^{13}$.

In an era in which we need new ways to treat UTI, strategies may include the use of probiotics. In female adults, probiotics have been studied and used for the health of urogenital tract in the area of urogenital infection ${ }^{29-30}$. In urogenital tract, the probiotic microflora ascend from rectal skin to urinary tract, kill uropathogens by hydrogen peroxide and bacteriocin-like compounds ${ }^{31}$, and reduce iron required by uropathogens but not lactobacilli by iron-withholding system such as siderophilins ${ }^{32}$.

In our study, all the tested strains showed great activity toward Lactobacillus plantarum used using agar well diffusion test. $L$. acidophilus and $L$. plantarum had inhibitory properties against E.coli, S. aureus, Streptococcus agalactiae, Streptococcus uberis, Salmonella enteritidis and Bacillus pumilus ${ }^{33}$.

Probiotics have shown to protect against variety of pathogens as E. coli ${ }^{34}$. On the other hand, none of the Lactobacillus spp. was reported to be able to inhibit the growth of $S$. enteritidis, $S$. typhimurium, E.coli and $S$. aureus ${ }^{35}$. The in-vitro antagonistic activity of Lactobacillus plantarum and its bacteriocins was examined against UTI pathogens; and it showed the greater inhibitory effect $(20 \mathrm{~mm})$ against Escherichia coli while the least activity $(9 \mathrm{~mm})$ was found against Streptococcus $s p^{36}$.

\section{CONCLUSION}

It is concluded from the present study that UTI is common in pregnant women (14\%). UTI incidence was quiet high in the 26-35 age. Parity may be possible factor affecting the incidence and prevalence rate of UTls among women. E.coli was the most common isolated organism. Thus, the present study has 
highlighted the importance of routine screening of pregnant women for UTI followed by culturing and sensitivity test for appropriate antimicrobial selection to reduce the serious complications of symptomatic UTI. The inhibitory effect of Lactobacillus plantarum on UTI pathogens appeared promising.

\section{ACKNOWLEDGEMENT}

We are thankful to $\mathrm{MMCH}$ for their kind support

\section{REFERENCES}

1. Dwyer $P L$, O'Reilly M. Recurrent urinary tract infection in the female. Curr. Opin. Obstet. Gynecol 2002; 14: pp.537-543.

2. Nowicki B. Urinary tract infection in pregnant women: old dogmas and current concepts regarding pathogenesis. Curr. Infect. Dis. Rep 2002; 4: pp.529 -535.

3. Delzell JE, Jr Lefevre ML. Urinary tract infections during pregnancy. Am. Fam. Physician 2000; 61: pp.713-721.

4. Mazor-Dray E, Levy A, Schlaeffer F, Sheiner E. Maternal urinary tract infection: is it independently associated with adverse pregnancy outcome? J. Matern. Fetal Neonatal Med 2009; 22: pp.124 -128.

5. Sujatha R, Nawani M. Prevalence of a symptomatic bacteriuria and its antibacterial susceptibility pattern among pregnant women attending the antenatal clinic at Kanpur, India. J Clin Diag Res 2014; 8(4): DC01- DC03.

6. Moulds RFW, Jeyasingham MS. Gentamicin: a great way to start. Australia Prescriber 2010; 33(5): pp.134-135.

7. Alzohairy M, Khadri H. Frequency and Antibiotic Susceptibility Pattern of Uro-Pathogens Isolated from Community and HospitalAcquired Infections in Saudi Arabia-A Prospective Case Study British J Medicine Med Res 2011; 1(2): pp. 45-56.

8. Uehara S, K. Monden K, Nomoto Y, Senso R; Kariyam, H. Kumon. International Journal of Microbiological Agent 2006; 285: pp.530-534.

9. Cheesbrough M. District laboratory practice in tropical countries, (Part 2), Cambridge, Univ. press. (2000). Cambridge low price editions.

10. Okonko I O, ljandipe L A, llusanya O A, et al .Incidence of urinary tract infection (UTI) among pregnant women in Ibadan, South-Western Nigeria. African J Biotechnol 2009; 8 (23): pp. 6649-6657.

11. National Committee for Clinical Laboratory Standards. Performance Standards for Antimicrobial Susceptibility Testing; Twenty-First Informational Supplement. Document M100-S21. 31(1) 2011. Wayne, Pennsylvania: NCCLS. Last accessed 4/11/2016.https://www.researchgate.net/file.PostFileLoader.html?i $d=50 f 0395$ de39d5e8368000022\&assetKey=AS\%3A27217991090 $5873 \% 401441904155623$.

12. Ashraf $M$, Arshad $M$, Siddique $M$, et al. In vitro screening of locally isolated lactobacillus species for probiotic properties. Pakistan Vet. J 2009; 29(4): pp.186-190.

13. Tandi G P, Rathore1 R K, Nain K, Chouhan O, Singh A, Dua $M$. To Study the Prescription Pattern of Antimicrobials in Urinary Tract Infection in Pregnant Women in a Tertiary Care Hospital. Sch. Acad. J. Pharm 2016; 5(3): pp.71-75.

14. Al- Sibai M H, Saha A, Rasheed P. Sociobiological correlates of bacteriuria in Saudi pregnant women. Public Health 1989; 103(2): pp. 113-121.

15. Abdullah A. A, Al-Moslih M. I. Prevalence of asymptomatic bacteriuria in pregnant women in Sharjah, Unite Arab Emirates. East Mediterr Health J 2005; 11(5-6): pp. 1045-1052.

16. Hazhir S. Asymptomatic bacteriuria in pregnant women. Urol $\mathrm{J}$ 2007; 4 (1) pp. 24-27.

17. Battikhi $M N$, and Battikhi Q G. Correlation of Urinary Tract Infection Pathogens, Antibiogram and Age Group in Pregnant Women. Journal of Microbiology \& Experimentation 2015; 2 (4).

18. Matuszkiewicz-Rowińska J, Małyszko J, Wieliczko M. Urinary tract infections in pregnancy: old and unresolved diagnostic and therapeutic problems. Arch Med Sci 2015; 11(1): pp.67-77.

19. Alex B, Peter E, Johnson N, et al. Asymptomatic urinary tract infections in pregnant women attending antenatal clinic in Cape Coast, Gana. E3 Journal of Medical Research 2012; 1(6): pp. 074083.

20. Al-Harthi A A, Al- Fifi S H. Antibiotic resistance pattern and empirical therapy for urinary tract infections in children. Saudi Med J 2008; 29(6): pp. 854-8.

21. Dash M, Padhi S, Mohanty I, Panda P, Parida P. Antimicrobial resistance in pathogen causing urinary tract infection in rural community of odisha, India. J family Community Medicine 2013; 20 (1): pp. 20-26.

22. Parveen K, Momen A, Ara Begum A, Begum M. Prevalence of urinary tract infection during pregnancy. J Dhoka National Med Coll Hos 2011; 17(2): pp.8-12.

23. O'Dell K K. Pharmacological management of asymptomatic bacteriuria and urinary tract infection in women. $\mathrm{J}$ Midwifery Womens Health 2011; 56(3): pp.248-265.

24. Awasthi A, Adiga P, Rao S. Prevalence of asymptomatic bacteriuria and sterile pyuria in pregnant women attending antenatal clinic in a tertiary care center in Karnataka. Clin Epidemiol Global Health 2013; 1 (44): p. 49.

25. Zeyaullah M D, Kaul V. Prevalence of urinary tract infection an antibiotic resistance pattern in SAUDI ARABIA population. Global Journal of Biology and Health Sciences 2015; 4(1): pp.206-214.

26. Memish Z A, Ahmed Q A, Arabi Y M, Shibl A M, Niederman M. S. Microbiology of community-acquired pneumonia in the Gulf Corporation Council states. J Chemother 2007; 19 (1): pp. 17-23.

27. Abdallah1 N, Elsayed S, Mostafa M, El-gohary G. Biofilm forming bacteria isolated from urinary tract infection, relation to catheterization and susceptibility to antibiotics. Intern J Biotechnol Molecular Biol Res 2011; 2(10): pp. 172-178.

28. Savas L, Guvel S, Onlen Y, Savas N, Duran N. Nosocomial urinary tract infections: micro-organisms, antibiotic sensitivities and risk factors. West Indian Med. J 2006; 55 (3): pp.188-193.

29. Reid G, Bruce A W, Fraser N, Heinemann C, Owen J, Henning B. Oral probiotics can resolve urogenital infections. FEMS Immunol Med Microbiol 2001;

30: pp.49-52.30. Gardiner G E, Heinemann C, Bruce A W, Beuerman D, Reid G. Persistence of Lactobacillus fermentum RC14 and Lactobacillus rhamnosus GR-1 but not L. rhamnosus GG in the human vagina as demonstrated by randomly amplified polymorphic DNA. Clin Diagn Lab Immunol 2002; 9: pp. 92-96.

31. McGroarty J A, Reid G. Detection of a Lactobacillus substance that inhibits Escherichia coli. Can J Microbiol 1988; 34: pp. 974-8. 32. Weinberg ED, Weinberg G A. The role of iron in infection. Curr Opin Infect Dis1995; 8: pp.164-9.

33. Murry A C, Hinton A, Buhr R J. Effect of Botanical Probiotic Containing Lactobacilli on Growth Performance and Populations of Bacteria in the Ceca Cloaca and Carcass Rinse of Broiler 
Chickens. Intern J Poultry Sci 2006; 5 (4): pp. 344-350.

34. Chateau N, Castellanous I, Deschamps A M. Distribution of pathogen inhibition in Lactobacillus isolates of a commercial probiotics consortium. J.Applied Bacteriol 1993; 74: pp. 36-40.

35. Koga T, Mizobe T, Takumi K. Antibacterial activity of Lactobacillus species against Vibrio species. Microbial. Res 1998; 153: pp. 271-275.

36. Selvamohan T, Sujitha S. Antimicrobial activity of a probiotic Lactobacillus Plantarum against urinary tract infection (UTI) causing pathogens. Der Pharmacia Lettre 2010; 2(5): pp.432-440 (http://scholarsresearchlibrary.com/DPL-vol2-iss5/DPL-2010-2-5432-440.pdf). Last accessed 4/11/2016.
Source of Support: Nil. Conflict of Interest: None Declared. Copyright: (c) the author(s) and publisher. IJMRP is an official publication of Ibn Sina Academy of Medieval Medicine \& Sciences, registered in 2001 under Indian Trusts Act, 1882.

This is an open access article distributed under the terms of the Creative Commons Attribution Non-commercial License, which permits unrestricted non-commercial use, distribution, and reproduction in any medium, provided the original work is properly cited.

Cite this article as: Maha A. Abo-Shadi, Amal S. Al-Johani. Microbial Profile and Antibiogram Pattern of UTI in Pregnant Women at a Saudi Hospital. Int J Med Res Prof. 2016; 2(6):74-80. DOI:10.21276/ijmrp.2016.2.6.014 